\title{
Environmental health risk assessment of nickel contamination of drinking water in a country
}

town in NSW

\author{
Noore Alam $^{\mathrm{A}, \mathrm{B}, \mathrm{C}}$, Stephen J. Corbett ${ }^{\mathrm{A}}$ \\ and Helen C. Ptolemy ${ }^{\mathrm{A}}$
}

${ }^{\mathrm{A}}$ Centre for Population Health, Sydney West Area Health Service ${ }^{\mathrm{B} N a t i o n a l ~ C e n t r e ~ f o r ~ E p i d e m i o l o g y ~ a n d ~ P o p u l a t i o n ~ H e a l t h ~}$ (NCEPH), Australian National University

CCorresponding author.Email: noore.alam@, cancerinstitute.org.au authority (LGA) treated the water before supplying it as drinking water to its residents.

Between 2002 and 2005, the water samples at Sampleton recorded on the NSW Health Drinking Water Database intermittently exceeded the Australian Drinking Water Guidelines (ADWG) value for nickel of $0.02 \mathrm{mg} / \mathrm{L} .^{1,2}$ The aim of this risk assessment was to assess the potential health risks associated with the consumption of drinking water with an elevated nickel concentration.

\section{Risk assessment methodology}

We used the enHealth Guidelines for Assessing Human Health Risks from Environmental Hazards (2002) as the risk assessment tool. ${ }^{3}$ The ADWG and the WHO guidelines for nickel were used for the specific guidelines on nickel levels in drinking water. ${ }^{2,4}$ Chemical analysis of water samples were undertaken by a laboratory accredited by the National Association of Testing Authorities (NATA). ${ }^{5}$ Laboratory test results for nickel in the water samples were compared with the ADWG and the WHO guidelines.

\section{Hazard assessment \\ Hazard identification}

Ground water can contain dissolved metals including nickel (Ni) and chemicals naturally released from rock and soil, which can be harmful to humans. ${ }^{6}$ The estimated average daily dietary intake of nickel is between $0.1 \mathrm{mg} /$ day and $0.3 \mathrm{mg} /$ day. $^{7,8}$ The intake of nickel from food is estimated to be less than $0.2 \mathrm{mg} /$ day. Drinking water generally contributes $5-25 \mu \mathrm{g}$ of nickel per day, which is approximately $2-11 \%$ of the total daily oral intake of nickel. ${ }^{4}$ In Australia, the concentration of nickel in typical drinking water is less than $0.01 \mathrm{mg} / \mathrm{L}$ with the highest allowable value of $0.02 \mathrm{mg} / \mathrm{L} .{ }^{9}$

Non-occupational sources of nickel exposure include food, air and water, but the amount of nickel found is usually much smaller than that typically found in occupational settings. ${ }^{10}$ The primary source of nickel in drinking water is from metal pipes and fittings in contact with drinking water. Nickel concentrations in ground water are influenced by soil type, $\mathrm{pH}$ level and sampling depth. ${ }^{4}$ Higher concentrations have been reported where drinking water is contaminated with nickel waste discharge from chemical, industrial or mining plants. ${ }^{9}$ 


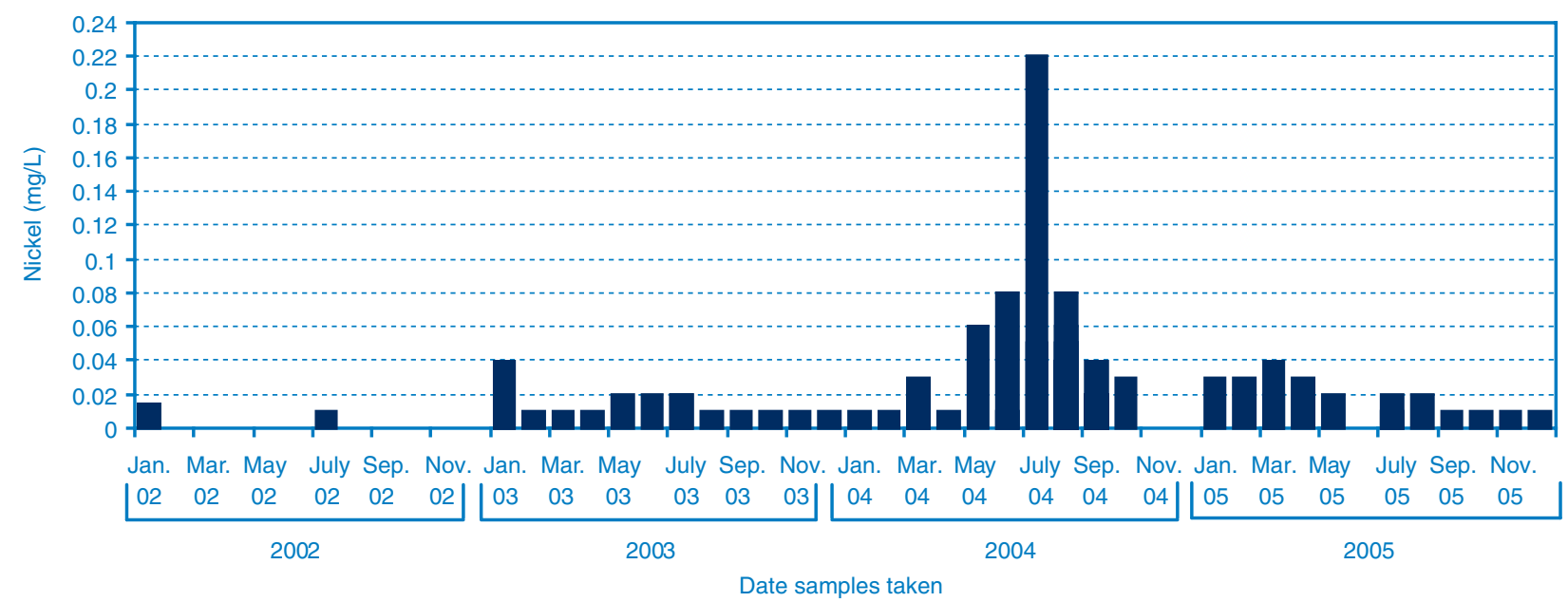

Figure 1. Concentration of nickel in samples of drinking water in Sampleton, NSW, 2002-2005.

The adverse health effects of nickel for humans depend upon the route of administration, water solubility (absorption) of nickel compounds, dose, bodyweight, sensitivity and duration of exposure ${ }^{4,11-13}$ Dermal exposure is the commonest cause of skin irritation to those allergic to nickel, with more females than males being affected. ${ }^{14}$ The main adverse effect for this risk assessment is nickel allergic dermatitis, as it occurs at very low levels of exposure. The Expert Group on Vitamins and Minerals estimated that approximately $7-10 \%$ of the population in the United Kingdom, predominantly women, have this condition. ${ }^{15}$ Allergic contact dermatitis due to nickel sensitivity increases with age and may affect as much as $4-5 \%$ of the paediatric population. ${ }^{16-18}$ While for some people the reactions are limited to a minor skin irritation, for certain sensitised people the exposure to elevated nickel may cause or aggravate dermatitis. In about half of the sensitive people with vesicular hand eczema, the reactions can be very severe and can lead to loss of working ability. ${ }^{15}$

\section{Dose-response assessment}

Assessing the dose-response relationship in terms of nickel sensitivity is complex. Christensen and Lagesson observed wide variations in nickel concentrations in blood and nickel excretion in urine in healthy humans when equal amounts of nickel were ingested. ${ }^{7}$ Such variation in sensitivity makes it difficult to estimate the true dose-response effect because a very small exposure to nickel may trigger a rapid response in some people due to their high level of sensitivity. The lowest observed adverse effect level (LOAEL) for an oral dose is reported to be $0.05 \mathrm{mg} / \mathrm{kg}$ bodyweight per day when skin is not sensitised. ${ }^{8}$ But when the skin is sensitised, an oral intake of $0.012 \mathrm{mg} / \mathrm{kg}$ bodyweight per day may provoke contact dermatitis. ${ }^{13}$

\section{Exposure assessment}

In Sampleton, the mean nickel concentration in drinking water found in water samples taken between January 2002 and December 2005 was $0.03 \mathrm{mg} / \mathrm{L}$ (95\% CI: 0.02-0.04) (Figure 1).

The high concentration of nickel appears to be a result of the introduction of mine water into the drinking water catchment and the reduction of the natural flow rate within the catchment due to the drought. The lowered flow rate in the catchment due to drought conditions was the main reason that the mine water was accessed to supplement the drinking water supply. The changes in nickel concentrations over the 3-year period could be attributed to changes in natural dilution and the level of demand of water sourced from the colliery to meet the supply requirements. ${ }^{19}$

\section{Risk characterisation}

The human health risk of nickel contamination of drinking water in Sampleton has been characterised in consideration of the following two guidelines:

\section{The Australian Drinking Water Guidelines}

The ADWG sets a safety standard value for concentration of nickel in drinking water. ${ }^{2}$ The guideline value was derived as follows:

$\frac{5 \mathrm{mg} / \mathrm{kg} \text { bodyweight per day } \times 70 \mathrm{~kg} \times 0.1}{2 \mathrm{~L} / \text { day } \times 1000}=0.02 \mathrm{mg} / \mathrm{L}$

where:

- $5 \mathrm{mg} / \mathrm{kg}$ bodyweight per day is the lowest observed adverse effect level (LOAEL) for altered organ-tobodyweight ratios based on animal studies ${ }^{20}$

- $70 \mathrm{~kg}$ is the average bodyweight of an adult

- 0.1 is the proportion of total daily intake attributable to the consumption of water

- $2 \mathrm{~L} /$ day is the average amount of water consumed by an adult

- 1000 is the safety factor used for the uncertainty over applying animal studies to humans. In this case, the 
safety value is applied as follows: 10 for interspecies variations, 10 for intraspecies variations and 10 to compensate for the lack of adequate studies on chronic effects and for increased intestinal absorption when taken on an empty stomach. ${ }^{2}$

\section{The WHO guidelines}

The WHO guidelines for drinking-water quality, based on human challenge studies done by Nielsen et al. (1999), recommend the safe nickel value in drinking water as $0.07 \mathrm{mg} / \mathrm{L}$, which was calculated as follows: ${ }^{4,13}$

$$
\frac{0.012 \mathrm{mg} / \mathrm{kg} \text { bodyweight } \times 60 \mathrm{~kg} \times 0.2}{2 \mathrm{~L} / \text { day }}=0.07 \mathrm{mg} / \mathrm{L}
$$

where:

- $0.012 \mathrm{mg} / \mathrm{kg}$ bodyweight, derived from a LOAEL based on human challenge studies ${ }^{13}$

- $60 \mathrm{~kg}$ is the average weight of an adult

- 0.2 is the proportion of total daily intake (TDI) of nickel from drinking water

- $2 \mathrm{~L} /$ day is the average amount of water consumed by an adult.

The WHO guidelines' value for nickel in drinking water is derived from the LOAEL of $0.012 \mathrm{mg} / \mathrm{kg}$ of bodyweight based on experiments in fasting adults with single doses on empty stomach. ${ }^{13}$ Because this LOAEL of $0.012 \mathrm{mg} / \mathrm{kg}$ bodyweight was based on a highly sensitive individuals, WHO did not include an uncertainty factor (intraspecies or interspecies variations) to derive the TDI. ${ }^{4}$ Using the LOAEL of $0.012 \mathrm{mg} / \mathrm{kg}$ bodyweight, the LOAEL for a $70-\mathrm{kg}$ adult would be $0.84 \mathrm{mg} / \mathrm{L}$ per day $(0.012 \mathrm{mg} / \mathrm{kg}$ bodyweight $\times 70 \mathrm{~kg})$.

To our knowledge, there are no data available on the LOAEL for nickel consumption in children. However, it is likely that the LOAEL for children would be greater than the adult LOAEL of $0.012 \mathrm{mg} / \mathrm{kg}$ bodyweight as this value was calculated on a highly nickel-sensitive adult population. ${ }^{13}$ Children are less likely to have been sensitised to nickel as nickel sensitivity increases with age. ${ }^{16-18}$ The average intake of $0.03 \mathrm{mg}$ nickel, assuming consumption of one litre of water each day and using the adult LOAEL of $0.012 \mathrm{mg} / \mathrm{kg}$ bodyweight would result in a childhood LOAEL of $0.16 \mathrm{mg} /$ day $(0.012 \mathrm{mg} / \mathrm{kg} \times 13 \mathrm{~kg})$ for a $13 \mathrm{~kg}$ child. $^{2}$

The mean nickel content $(0.03 \mathrm{mg} / \mathrm{L})$ in the drinking water in Sampleton was one and a half times higher than the ADWG value but accounts for only $43 \%$ of the WHO guidelines value. The higher nickel level in Sampleton water was intermittent, with one-third of the total water samples tested exceeding the ADWG value over a 4-year period. The ADWG is based on animal studies that, when applied to humans, provide only persuasive rather than hard evidence for effects on humans. ${ }^{2,20}$ The animal data may also not be sufficiently protective of people sensitised to nickel. The WHO guidelines value $(0.07 \mathrm{mg} / \mathrm{L})$, on the other hand, is the maximum effect value based upon experiments on nickelsensitive people at a fasting state. Assuming a 70-kg adult drinks $2 \mathrm{~L}$ of water per day, the average daily intake of $0.06 \mathrm{mg}(0.03 \mathrm{mg} \times 2 \mathrm{~L})$ of nickel from drinking water in Sampleton was approximately $7 \%$ of the LOAEL of $0.84 \mathrm{mg}$ $(0.012 \times 70 \mathrm{~kg})$ based on experiments on nickel-sensitive adults at fasting state. ${ }^{13}$ In children, it is difficult to provide a meaningful calculation of the risk as childhood bodyweights and consumption of drinking water are highly variable. However, assuming consumption of one litre of water per day, the average daily intake of $0.03 \mathrm{mg}$ of nickel from drinking water in Sampleton was approximately $19 \%$ of the LOAEL of $0.16 \mathrm{mg} /$ day $(0.012 \mathrm{mg} / \mathrm{kg} \times 13 \mathrm{~kg})$ estimated for a 2-year-old child weighing $13 \mathrm{~kg}$.

Assuming that the dietary intake of nickel in the Sampleton population is no different from that in the Australian population, and that the residents of Sampleton are all nickel-sensitive (which is unlikely), the mean nickel concentration of $0.03 \mathrm{mg} / \mathrm{L}$ (95\% CI: 0.02-0.04) appears to have no health risks for the inhabitants of Sampleton.

The single high reading in the 4-year period of $0.22 \mathrm{mg} / \mathrm{L}$ in July 2004 (Figure 1) could have been due to a sampling error or measurement (laboratory) error. The particular sample was taken from the same outlet as all the other samples over the sampling period, so it is unlikely that there was an increase in nickel level due to other contamination sources such as plumbing. However, the nickel value of $0.22 \mathrm{mg} / \mathrm{L}$ at the daily intake rate of $2 \mathrm{~L}$ a day of drinking water for a $70-\mathrm{kg}$ adult would still be only $52 \%$ of the LOAEL of $0.84 \mathrm{mg} /$ day $(0.012 \times 70 \mathrm{~kg})$ for adults based on studies of nickel-sensitive people. ${ }^{13}$ For children, the observed nickel value of $0.22 \mathrm{mg} / \mathrm{L}$ at the daily intake of $1 \mathrm{~L}$ a day for a $13 \mathrm{~kg}$ child would be $138 \%$ of the childhood LOAEL of $0.16 \mathrm{mg} /$ day $(0.012 \mathrm{mg} / \mathrm{kg}$ bodyweight $\times 13 \mathrm{~kg}) .{ }^{9}$ However, the LOAEL for highly-sensitive adults used in this calculation provides a safety factor for young children as they are less likely to be highly sensitised to nickel. Therefore, it is unlikely that this level of nickel in drinking water would have a significant effect on the younger population.

\section{Risk management}

Although the risk assessment found no obvious threat to the health of Sampleton residents, the LGA has been informed of the need to continue to monitor the water supply for nickel levels. The Council was advised that, under the NSW Health Drinking Water Monitoring Program, monitoring of the quality of drinking water should rotate between designated sample sites throughout the distribution system and over time. ${ }^{1}$ 


\section{Conclusion}

An enhanced surveillance of the chemical concentrations in the town water supply system has been recommended while mine water is being directed to the drinking water catchment. The use of alternative sources to supplement drinking water supplies during drought conditions, such as mine water in this case, may become more common in rural and regional towns as the drought conditions and water supply levels continue to fluctuate. While this risk assessment provides some reassurance that small increases in nickel in this town water supply are not a hazard to human health, the study does highlight the need for continued vigilance in relation to water quality when water scarcity forces supply authorities to choose alternative sources.

\section{Acknowledgment}

The authors would like to thank Ms Amanda Muir and the environmental health team at the local council for collecting water samples. Thanks to the Centre for Population Health, Sydney West Area Health Service for support in this assessment.

\section{References}

1. NSW Department of Health. NSW Health Drinking Water Monitoring Program. State Health Publication No: (EH) 050175. Sydney: NSW Department of Health; 2005.

2. National Health and Medical Research Council and Natural Resource Management Ministerial Council. Fact Sheets: Physical and Chemical Characteristics. Australian Drinking Water Guidelines 2004. Canberra: NHMRC; 2004. Available from: http://www.nhmrc.gov.au/publications/ synopses/eh19syn.htm (Cited 23 June 2008.)

3. Department of Health and Ageing and enHealth Council. Environmental health risk assessment: guidelines for assessing human health risks from environmental hazards. Canberra: Commonwealth of Australia; 2002.

4. World Health Organization. Nickel in drinking-water (WHO/SDE/WSH/05.08/55). Available from: http://www.who.int/water_sanitation_health/gdwqrevision/ nickel2005.pdf (Cited 24 October 2008.)

5. National Association of Testing Authorities. Home page. Silverwater, NSW: National Association of Testing Authorities; 2005. Available from: http://www.nata.asn.au/ (Cited 6 October 2005.)

6. Lehr J, Hyman M, Gass TE, Seevers W. Handbook of complex environmental remediation problems. New York: McGraw Hill; 2002.

7. Christensen OB, Lagesson V. Nickel concentration of blood and urine after oral administration. Ann Clin Lab Sci 1981; 11: $119-25$.
8. Committee on Toxicity of Chemicals in Food Consumer Products and the Environment. Nickel leaching from kettle elements into boiled water. London: Committee on Toxicity; 2003. Available from: http://www.food.gov.uk/ multimedia/pdfs/2003-02.pdf (Cited 24 October 2008.)

9. National Health and Medical Research Council and Natural Resource Management Ministerial Council. Fact Sheets: Physical and Chemical Characteristics. Australian Drinking Water Guidelines. Canberra: NHMRC; 2004. Available from: http://www.nhmrc.gov.au/publications/synopses/_files/adwg 11_06_fact_sheets.pdf (Cited 22 June 2008.)

10. International Agency for Research on Cancer. IARC Monographs on the evaluation of carcinogenetic risks to humans: chromium, nickel and welding: 49. Health Organization: Geneva; 1997.

11. Andersen KE, Benezra C, Burrows D et al. Contact dermatitis. A review. Contact Dermatitis 1987; 16: 55-78. doi:10.1111/j.1600-0536.1987.tb01382.x

12. Grimsrud TK, Berge SR, Haldorsen T et al. Can lung cancer risk among nickel refinery workers be explained by occupational exposures other than nickel? Epidemiology 2005; 16 : 146-54. doi:10.1097/01.ede.0000152902.48916.d7

13. Nielsen GD, Soderberg U, Jorgensen PJ et al. Absorption and retention of nickel from drinking water in relation to food intake and nickel sensitivity. Toxicol Appl Pharmacol 1999; 154: 67-75. doi:10.1006/taap.1998.8577

14. Sharma AD. Relationship between nickel allergy and diet. Indian J Dermatol Venereol Leprol 2007; 73: 307-12.

15. Expert Group on Vitamins and Minerals (EVM). Risk assessment: Nickel. London: EVM; 2003. Available from: http://www.food.gov.uk/multimedia/pdfs/evm_nickel.pdf (Cited 24 October 2008.)

16. Beattie PE, Green C, Lowe G, Lewis-Jones MS. Which children should we patch test? Clin Exp Dermatol 2006; 32: $6-11$.

17. Militello G, Jacob SE, Crawford GH. Allergic contact dermatitis in children. Curr Opin Pediatr 2006; 18: 385-90. doi:10.1097/01.mop.0000236387.56709.6d

18. Silverberg NB, Licht J, Friedler S et al. Nickel contact hypersensitivity in children. Pediatr Dermatol 2002; 19 : 110-3. doi:10.1046/j.1525-1470.2002.00057.x

19. Lithgow City Council. Lithgow City Council Drought Management Strategy. Lithgow: Lithgow City Council; 2008. Available from: http://www.council.lithgow.com/ reg_fishriver.html (Cited 21 May 2008.)

20. Ambrose AM, Larson PS, Borzelleca JF, Hennigar GR. Long term toxicologic assessment of nickel in rats and dogs. J Food Sci Technol 1976; 13: 181-7. 